\title{
Theoretical Study of Mixed Hydrogen and Dihydrogen Bond Interactions in $\mathrm{BH}_{4}\left(\mathrm{NH}_{3}\right)_{n}{ }^{-}$Clusters
}

\author{
Abedien Zabardasti, ${ }^{1}$ Nahid Zare, ${ }^{1}$ Masoumeh Arabpour, ${ }^{1}$ \\ Ali Kakanejadifard, ${ }^{1}$ and Mohammad Solimannejad ${ }^{2}$ \\ ${ }^{1}$ Department of Chemistry, Lorestan University, Khoramabad, Iran \\ ${ }^{2}$ Quantum Chemistry Group, Department of Chemistry, Faculty of Sciences, Arak University, \\ Arak 38156-8-8349, Iran \\ Correspondence should be addressed to Abedien Zabardasti; zebardasti@yahoo.com
}

Received 2 May 2013; Accepted 26 June 2013

Academic Editor: Ewa Schab-Balcerzak

Copyright (C) 2013 Abedien Zabardasti et al. This is an open access article distributed under the Creative Commons Attribution License, which permits unrestricted use, distribution, and reproduction in any medium, provided the original work is properly cited.

\begin{abstract}
$\mathrm{Ab}$ initio calculations were used to analyze interactions of $\mathrm{BH}_{4}^{-}$with 1-4 molecules of $\mathrm{NH}_{3}$ at the MP2/6-311++G(d,p) and the B3LYP/6-311++G(d,p) computational levels. In addition to $\mathrm{H}_{3} \mathrm{~B}-\mathrm{H} \cdots \mathrm{H}-\mathrm{NH}_{2}$ dihydrogen bond, the $\mathrm{H}_{2} \mathrm{~N}-\mathrm{H} \cdots \mathrm{NH}_{3}$ hydrogen bonds were also predicted in clusters. Negative cooperativity in clusters constructed from mixed $\mathrm{H}_{3} \mathrm{~B}-\mathrm{H} \cdots \mathrm{H}-\mathrm{NH}_{2}$ dihydrogen and $\mathrm{H}_{2} \mathrm{~N}-\mathrm{H} \cdots \mathrm{NH}_{3}$ hydrogen bonds are more remarkable. The negative cooperativity increases with size and number of hydrogen bonds in cluster. The B-H stretching frequencies show blue shifts with respect to cluster formation. Greater blue shift in stretching frequencies was predicted for $\mathrm{B}-\mathrm{H}$ bonds which did not contribute to dihydrogen bonding with $\mathrm{NH}_{3}$ molecules. The structures were analyzed with the atoms in molecules (AIM) methodology.
\end{abstract}

\section{Introduction}

Hydrogen is an ideal energy carrier; therefore, the binary boron-hydrogen compounds or boranes are the core of hydrogen storage and are an extremely rich area of boronbased cluster chemistry. In addition, the borohydride complexes $\mathrm{NaBH}_{4}$ and $\mathrm{LiBH}_{4}$ possess a high capacity for hydrogen retention, and the release of hydrogen from $\mathrm{NaBH}_{4}$ is only possible via hydrolysis [1-4]. Many salts of this anion, such as $\mathrm{LiBH}_{4}$ and $\mathrm{NaBH}_{4}$, are essentially ionic and have been used for nearly 60 years as reducing agents [5].

Despite extensive experimental and theoretical studies on dihydrogen (DHB) and hydrogen bonded (HB) complexes [6-18], few studies were simultaneously oriented toward systems containing both DHB and HB interactions [19].

An important aspect of $\mathrm{HB}$ and $\mathrm{DHB}$ interactions is their cooperativity or negative cooperativity (anticooperativity) when increasing the number of $\mathrm{H} \cdots \mathrm{X}$ or $\mathrm{H} \cdots \mathrm{H}$ contacts in self-association of molecular systems [20-23].
Quantum-chemical calculations performed on dimers, trimers, and more complicated self-associates of simple molecules, like $\mathrm{H}_{2} \mathrm{O}$ and $\mathrm{HCN}$, revealed that the hydrogenbonding energies in the linear associates are remarkably higher than the values in dimers, which is due to mutual polarization of bonds. This cooperativity effect increases with the chain length of the associates. In contrast to those aforementioned, theoretical investigations of branched complexes in which two or more hydrogen bonds are formed by one proton-acceptor group predicted an inverse effect. In this case, mutual polarization weakens the hydrogen bonds, leading to negative cooperativity [24-26]. Moreover, presence of cooperativity in DHB clusters has been reported recently [7]. The aim of this work is to investigate the binding energy and cooperativity of systems containing mixed DHB and $\mathrm{HB}$ interactions. For this purpose, the model clusters $\mathrm{BH}_{4}\left(\mathrm{NH}_{3}\right)_{n}{ }^{-}, n=1-4$, have been considered. Moderate negative charge of $\mathrm{BH}_{4}{ }^{-}$allows the coexistence of both $\mathrm{HB}$ and $\mathrm{DHB}$ interactions in the cluster. $\mathrm{Ab}$ initio and DFT calculations for such complexes were 

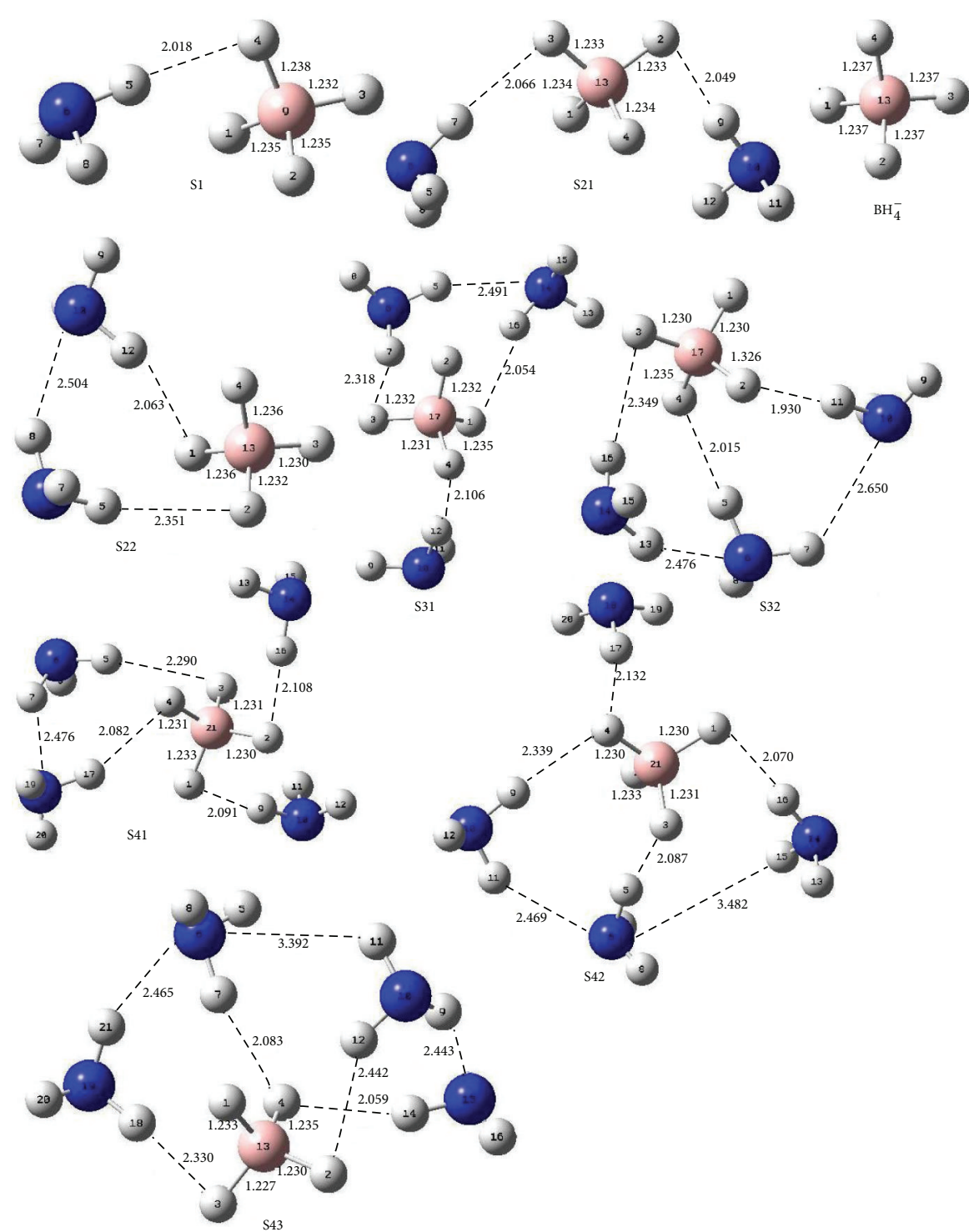

FIGURE 1: Geometries of clusters of $\mathrm{BH}_{4}{ }^{-}$with $\mathrm{NH}_{3}$ optimized at MP2/6-311++g(d,p) level.

performed, and the Bader theory was applied to analyze $\mathrm{H} \cdot \mathrm{H}$ interactions.

\section{Computational Methods}

Calculations were performed using the Gaussian 03 package of codes [27]. The geometries of the isolated $\mathrm{BH}_{4}{ }^{-}$and $\mathrm{NH}_{3}$ moieties and their complexes were fully optimized at the MP2/6-311++G(d,p) and the B3LYP/6-311++G(d,p) computational levels. Both MP2 and B3LYP computations have their own supporting instances from the point of agreement between theoretical prediction and experimental measurement $[28,29]$. Harmonic vibration frequency calculations at MP2/6-311++G(d,p) and B3LYP/6-311++G(d,p) levels confirmed the structures as minima and enabled the evaluation of zero-point vibration energies (ZPVE). The counterpoise procedure [30] was used to correct the interaction energy for basis set superposition error (BSSE). The AIM2000 package [31] was used to obtain bond properties and to plot molecular graphs.

\section{Results and Discussion}

Figure 1 illustrates optimized geometries for clusters which could be obtained from the interaction of $\mathrm{BH}_{4}{ }^{-}$with up to 4 molecules of $\mathrm{NH}_{3}$.

Association of $\mathrm{BH}_{4}{ }^{-}$with one molecule of the $\mathrm{NH}_{3}$ gives a 1:1 cluster which is denoted S1.

For a 1:2 ratio the S21 and S22 clusters were predicted, and the $\mathrm{S} 21$ has two discrete $\left(\mathrm{H}_{2} \mathrm{~N}-\mathrm{H} \cdots \mathrm{H}-\mathrm{B}\right)$ dihydrogen bonds. The S22 could be considered as a cluster which is obtained from interaction of an $\mathrm{H}_{2} \mathrm{~N}-\mathrm{H} \cdots \mathrm{NH}_{3}$ dimer with a $\mathrm{BH}_{4}{ }^{-}$ion, and it consists of two DHBs and an HB interaction. The stability of S22 because of the presence of an additional 
TABLE 1: BSSE, stabilization energy corrected with ZPE, uncorrected stabilization energy, and cooperative effect (CE) calculated at MP2/6-311++G(d,p).

\begin{tabular}{lcccc}
\hline Cluster & $\begin{array}{c}\mathrm{BSSE} \\
\mathrm{kcal} \mathrm{mol}^{-1}\end{array}$ & $\begin{array}{c}\mathrm{SE} \text { (uncorr.) } \\
\mathrm{kcal} \mathrm{mol}^{-1}\end{array}$ & $\begin{array}{c}\mathrm{SE} \text { (corr.) } \\
\mathrm{kcal} \mathrm{mol}^{-1}\end{array}$ & $\begin{array}{c}\mathrm{CE} \\
\mathrm{kcal} \mathrm{mol}^{-1}\end{array}$ \\
\hline S1 & 0.83 & -7.87 & -6.54 & - \\
S21 & 1.66 & -15.24 & -12.59 & 0.49 \\
S22 & 2.37 & -16.20 & -12.78 & 2.48 \\
S31 & 3.18 & -23.33 & -18.71 & 3.09 \\
S32 & 3.56 & -23.57 & -18.63 & 3.16 \\
S41 & 3.94 & -29.83 & -24.31 & 4.02 \\
S42 & 4.12 & -29.83 & -24.12 & 4.20 \\
S43 & 4.77 & -30.10 & -24.69 & 5.82 \\
\hline
\end{tabular}

$\left(\mathrm{H}_{2} \mathrm{~N}-\mathrm{H} \cdots \mathrm{NH}_{3}\right)$ hydrogen bond is slightly greater than the stability of S21 (Tables 1 and 2).

For a 1:3 ratio S31 and S32 clusters at MP2 and B3LYP levels were optimized. The S31 has three DHBs and a hydrogen bond interaction and is aggregated from interactions of a $\mathrm{H}_{2} \mathrm{~N}-\mathrm{H} \cdots \mathrm{NH}_{3}$ and an $\mathrm{NH}_{3}$ molecule with a $\mathrm{BH}_{4}{ }^{-}$ion. The $\mathrm{S} 32$ is optimized from the interaction of a chain of $\left(\mathrm{NH}_{3}\right)_{3}$ trimer with a $\mathrm{BH}_{4}{ }^{-}$, and its stability is in the order of S31 cluster.

In a 1: 4 mole ratio, the starting geometries go to $S 41, S 42$, and S43 at two levels of computations. The S41 was assembled from interactions of an $\mathrm{H}_{2} \mathrm{~N}-\mathrm{H} \cdots \mathrm{NH}_{3}$ dimer and two separated $\mathrm{NH}_{3}$ molecules with $\mathrm{BH}_{4}{ }^{-}$and consists of four DHBs and an HB interaction. The S42 that consist of four DHBs and an $\mathrm{HB}$ interaction might be considered as complexation between an S32 with an $\mathrm{NH}_{3}$ molecule. Of course, The AIM analysis shows a weak $\mathrm{NH}_{3} \cdots \mathrm{NH}_{3}$ interaction with a bond length of 3.482 in S42 that it might not be considered as an $\mathrm{HB}$ interaction, usually $\mathrm{HB}$ interactions have bond lengths around 1.7-2.4 $\AA$. The S43 might be considered as interactions of two $\mathrm{NH}_{3} \cdots \mathrm{NH}_{3}$ dimers with $\mathrm{BH}_{4}{ }^{-}$and consist of four DHB and two HB interactions. Also AIM analysis revealed a weak $\mathrm{NH}_{3} \cdots \mathrm{NH}_{3}$ interaction with a bond length of 3.392 in S43; therefore, it was not considered as an HB interaction. The stability of $1: 4$ complexes are close together, see Tables 1 and 2 , and it shows that $\mathrm{NH}_{3} \cdots \mathrm{NH}_{3}$ interactions are too weak; therefore, they did not have considerable effects on the stabilities of corresponding clusters. According to data given in Tables 1 and 2, stabilities of clusters increased with increasing the cluster size.

Results of intra and intermolecular bond lengths are given in Figure 1 and Table 3. At MP2 level, the $\mathrm{H} \cdots \mathrm{H}$ distance in S1 is 2.018 which for similar bonds increased to 2.066 and 2.049 in S21, 2.106 in S31, 2.091 and 2.108 in S41 and 2.070 and 2.132 in S42 complexes. Similarly, at B3LYP level the $\mathrm{H} \cdot \mathrm{H}$ distance in S1 is 1.991 which rose to 2.008 and 2.011 in S21, 2.015 in S31, 2.028 and 2.155 in S41 and 2.110 in S42 complexes. Elongation of $\mathrm{H} \cdot \cdots \mathrm{H}$ bonds show that it weakens with increasing the cluster size. Also, comparing $\mathrm{H} \cdots \mathrm{H}$ distances in S22, S31, S41, S42, and S43 complexes showed that $\mathrm{NH}_{3}$ molecules in $\mathrm{NH}_{3} \cdots \mathrm{NH}_{3}$ dimers have different
TABLE 2: BSSE, stabilization energy corrected with ZPE, uncorrected stabilization energy, and cooperative effect (CE) calculated at B3LYP/6-311++G(d,p).

\begin{tabular}{lcccc}
\hline Cluster & $\begin{array}{c}\mathrm{BSSE} \\
\mathrm{kcal} \mathrm{mol}^{-1}\end{array}$ & $\begin{array}{c}\mathrm{SE} \text { (uncorr.) } \\
\mathrm{kcal} \mathrm{mol}^{-1}\end{array}$ & $\begin{array}{c}\mathrm{SE} \text { (corr.) } \\
\mathrm{kcal} \mathrm{mol}^{-1}\end{array}$ & $\begin{array}{c}\mathrm{CE} \\
\mathrm{kcal} \mathrm{mol}^{-1}\end{array}$ \\
\hline S1 & 0.10 & -6.93 & -5.50 & - \\
S21 & 0.22 & -13.33 & -10.58 & 0.42 \\
S22 & 0.23 & -13.34 & -10.60 & 2.16 \\
S31 & 0.28 & -19.29 & -14.96 & 3.30 \\
S32 & 0.54 & -19.51 & -15.40 & 4.62 \\
S41 & 0.67 & -24.80 & -19.43 & 4.33 \\
S42 & 0.67 & -25.03 & -19.45 & 4.32 \\
S43 & 0.84 & -25.69 & -19.60 & 5.91 \\
\hline
\end{tabular}

TABLE 3: Bond lengths $(\AA)$ of hydrogen bonded clusters at B3LYP/6$311++\mathrm{G}(\mathrm{d}, \mathrm{p})$ level.

\begin{tabular}{lccccc}
\hline & $\mathrm{H} \cdots \mathrm{H}$ & $\mathrm{B}-\mathrm{H} 1$ & $\mathrm{~B}-\mathrm{H} 2$ & $\mathrm{~B}-\mathrm{H} 3$ & $\mathrm{~B}-\mathrm{H} 4$ \\
\hline $\mathrm{BH}_{4}{ }^{-}$ & - & 1.238 & 1.238 & 1.238 & 1.238 \\
$\mathrm{~S} 1$ & 1.991 & 1.236 & 1.236 & 1.233 & 1.240 \\
$\mathrm{~S} 21$ & $2.008,2.011$ & 1.234 & 1.235 & 1.235 & 1.234 \\
$\mathrm{~S} 22$ & $2.012,2.012$ & 1.238 & 1.235 & 1.231 & 1.234 \\
$\mathrm{~S} 31$ & $1.984,2.015,2.187$ & 1.229 & 1.237 & 1.230 & 1.236 \\
$\mathrm{~S} 32$ & $2.051,2.029,2.031$ & 1.233 & 1.233 & 1.233 & 1.233 \\
$\mathrm{~S} 41$ & $2.027,2.155,2.173,2.283$ & 1.232 & 2.231 & 2.232 & 2.232 \\
$\mathrm{~S} 42$ & $2.016,2.110,2.116,2.327$ & 1.232 & 1.232 & 1.231 & 1.232 \\
$\mathrm{~S} 43$ & $2.654,2.246,2.176,2.172$ & 1.234 & 1.231 & 1.228 & 1.235 \\
\hline
\end{tabular}

abilities for DHB interactions with $\mathrm{BH}_{4}{ }^{-}$. Results indicated that the $\mathrm{NH}_{3}$ molecules which are located in the head of these dimers have a greater tendency for DHB. In contrast, the $\mathrm{NH}_{3}$ at the end of these dimers has a smaller tendency for $\mathrm{DHB}$ interaction with $\mathrm{BH}_{4}{ }^{-}$in the related clusters. For example, at the MP2 level the $\mathrm{H} \cdot \mathrm{H}$ bond lengths for the first (head) and second (tail) $\mathrm{NH}_{3}$ in the S22 are 2.063 and 2.351, respectively. They show that the interaction of $\mathrm{BH}_{4}{ }^{-}$ with the first $\mathrm{NH}_{3}$ molecule is stronger than the second one. Similarly, in S31, S32, S41, S42, and S43 clusters the DHB lengths for the first $\mathrm{NH}_{3}$ of $\mathrm{NH}_{3} \cdots \mathrm{NH}_{3}$ dimers are 2.054, 2.015, 2.082, 2.087, and 2.059 and 2.083 while for the tail $\mathrm{NH}_{3}$ bond lengths increased to 2.318, 2.349, 2.290, 2.339, and 2.330 and 2.442 , respectively. Thus, stronger interactions for the first $\mathrm{NH}_{3}$ in $\mathrm{NH}_{3} \cdots \mathrm{NH}_{3}$ dimers could be deduced for these clusters. Such the conclusion might also be received from results of B3LYP level. It seems the presence of cooperativity in $\mathrm{HB}$ part of $\mathrm{NH}_{3} \cdots \mathrm{NH}_{3}$ chains is responsible for this behavior.

The $\mathrm{B}-\mathrm{H}$ bonds lengths in $\mathrm{BH}_{4}{ }^{-}$are 1.237 and 1.238 at MP2 and B3LYP levels, respectively. Comparison of these bond lengths with predicted values in optimized clusters requires dealing with the shortening of $\mathrm{B}-\mathrm{H}$ bonds upon cluster formation. Often contraction of $\mathrm{B}-\mathrm{H}$ bonds with stronger $\mathrm{H} \cdots \mathrm{H}$ interactions is less sizeable. For example, 
TABLE 4: Unscaled vibration frequencies $\left(\mathrm{cm}^{-1}\right)$ with corresponding intensities (values given in parenthesis, $\mathrm{km} \mathrm{mol}^{-1}$ ) of $\mathrm{HB}_{\mathrm{clusters}}$ calculated at MP2/6-311++G(d,p) level.

\begin{tabular}{|c|c|c|c|c|c|}
\hline \multirow{2}{*}{ cluster } & \multirow{2}{*}{$\nu \mathrm{H} \cdots \mathrm{H}$} & \multicolumn{4}{|c|}{$\nu_{\mathrm{B}-\mathrm{H}}$} \\
\hline & & $\mathrm{B}-\mathrm{H} 1$ & $\mathrm{~B}-\mathrm{H} 2$ & $\mathrm{~B}-\mathrm{H} 3$ & $\mathrm{~B}-\mathrm{H} 4$ \\
\hline $\mathrm{BH}_{4}^{-}$ & - & $2311(637)$ & $2311(637)$ & $2311(637)$ & $2311(637)$ \\
\hline S1 & $201(8)$ & $2321(197)$ & $2325(544)$ & $2347(533)$ & $2303(409)$ \\
\hline S21 & $144(60), 170(60)$ & $2327(20)$ & $2336(444)$ & $2340(615)$ & $2341(435)$ \\
\hline S22 & $170(37), 182(35)$ & $2320(187)$ & $2344(384)$ & $2364(520)$ & $2326(440)$ \\
\hline S31 & $149(18), 150(21), 184(64)$ & $2330(141)$ & $2357(474)$ & $2357(474)$ & $2359(499)$ \\
\hline S32 & 192 (12), 202 (11) & $2372(494)$ & $2325(191)$ & $2358(362)$ & $2332(379)$ \\
\hline S41 & $158(34), 176(50), 197(18)$ & $2338(53)$ & $2355(312)$ & $2363(456)$ & $2368(472)$ \\
\hline S42 & $164(42), 170(42), 210(13)$ & $2349(309)$ & $2368(384)$ & $2386(469)$ & $2332(153)$ \\
\hline S43 & $162(30), 170(41), 177(20)$ & $2348(309)$ & $2367(384)$ & $2386(469)$ & $2332(153)$ \\
\hline
\end{tabular}

TABLE 5: Unscaled vibration frequencies $\left(\mathrm{cm}^{-1}\right)$ with corresponding intensities (values given in parenthesis, $\mathrm{km} \mathrm{mol}^{-1}$ ) of $\mathrm{HB}_{\mathrm{clusters}}$ calculated at B3LYP/6-311++G(d,p) level.

\begin{tabular}{|c|c|c|c|c|c|}
\hline \multirow{2}{*}{ Cluster } & \multirow{2}{*}{$\nu \mathrm{H} \cdots \mathrm{H}$} & \multicolumn{4}{|c|}{$v_{\mathrm{B}-\mathrm{H}}$} \\
\hline & & B-H1 & $\mathrm{B}-\mathrm{H} 2$ & $\mathrm{~B}-\mathrm{H} 3$ & $\mathrm{~B}-\mathrm{H} 4$ \\
\hline $\mathrm{BH}_{4}^{-}$ & - & $2224(567)$ & $2224(567)$ & $2224(567)$ & $2224(567)$ \\
\hline S1 & $201(18)$ & $2246(575)$ & $2258(490)$ & $2275(133)$ & $2224(568)$ \\
\hline S21 & $120(17), 133(65)$ & $2263(501)$ & $2255(704)$ & $2255(704)$ & $2263(501)$ \\
\hline S22 & $103(20), 175(42)$ & $2242(518)$ & $2259(500)$ & $2289(169)$ & $2270(407)$ \\
\hline S31 & $157(26), 173(33), 198(15)$ & $2304(234)$ & $2248(423)$ & $2293(456)$ & $2259(413)$ \\
\hline S32 & $176(30), 180(62), 194(32)$ & $2272(391)$ & $2274(521)$ & $2273(537)$ & $2273(391)$ \\
\hline S41 & $151(34), 171(41), 176(47), 195(43)$ & $2285(550)$ & $2287(399)$ & $2285(550)$ & $2287(399)$ \\
\hline S42 & $138(24), 171(13)$ & $2280(431)$ & $2283(547)$ & $2287(401)$ & $2297(21)$ \\
\hline S43 & $163(30), 165(42), 170(41), 177(20)$ & $2348(309)$ & $2367(384)$ & $2386(469)$ & $2332(153)$ \\
\hline
\end{tabular}

B-H1 (S22, S31), B-H2 (S32), and B-H4 (S1 and S32) have less contraction at MP2 level. The predicted changes of bond distances are in the same direction in both MP2 and B3LYP levels, see Figure 1 and Table 3.

The selected vibration stretching frequencies $\left(\mathrm{cm}^{-1}\right)$ with corresponding intensities $\left(\mathrm{km} \mathrm{mol}^{-1}\right)$ for clusters at two levels are given in Tables 4 and 5 . In B-H bonds, except for S1(B$\mathrm{H} 4$ ) that shows a red shift with respect to free $\mathrm{BH}_{4}{ }^{-}$at the MP2 level, in the other cases blue shifts for B-H stretching frequencies were predicted. Also in agreement with bond contractions greater blue shifts are corresponding to $\mathrm{B}-\mathrm{H}$ bonds that did not contribute to $\mathrm{H} \cdots \mathrm{H}$ interactions [32, 33].

The shortening of $\mathrm{B}-\mathrm{H}$ bonds and blue shifts of their stretching frequencies might be ascribed to the diminishing of their $\sigma \rightarrow \sigma^{*}$ transition which is due to the interaction of $\mathrm{BH}_{4}{ }^{-}$with $\mathrm{NH}_{3}$ molecules.

Results indicate that the stabilities of predicted clusters are not consistent with cooperative effects (CEs), and cooperative effect is defined as $\Delta E_{\mathrm{CE}}=\Delta E_{\text {cluster }}-\Sigma \Delta E_{\text {dimer }}$, where the sum is over the $1: 1$ clusters that make up the original complex [34], which means if the cluster S21 is considered to consist of two $1: 1$ clusters, then $\Delta E_{\mathrm{CES} 21}=\Delta E_{S 21}-$ $2 \Delta E_{S 1}=-12.59-2 \times(-6.54)=0.49$ which is partially consistent with negative cooperativity. Since presence of cooperativity results in negative values of $\mathrm{CE}$, the positive values of CEs gathered in Tables 1 and 2 return to negative cooperativity for corresponding clusters. This negative cooperativity enhanced by increasing the cluster size. The CE of S21 is 0.49 which increased to 3.16 in $3: 1$ clusters and 5.82 in $4: 1$ clusters. Competition of several $\mathrm{NH}_{3}$ molecules for taking electron density from $\mathrm{BH}_{4}{ }^{-}$does not hold a chance for DHB interactions and leads to negative cooperativity in these clusters.

Data given in Tables 1 and 2 show that CE inversely changes with the number of hydrogen bonds in the clusters. For instance, S21 does not have an HB but S22 has an HB, and their CEs are 0.49 and 2.48, respectively. This shows that structures with further $\mathrm{HBs}$ have more negative cooperativity with respect to structures with less HBs.

Also, the nature of $\mathrm{CE}$ for greater clusters might be deduced from their smaller ones. If we propose the $S 31$ as a combination of $\mathrm{S} 1$ and $\mathrm{S} 22$, then $\Delta E_{\mathrm{CE}(\mathrm{S} 31)}=\Delta E_{(\mathrm{S} 31)}-$ $\left(\Delta E_{(\mathrm{S} 22)}+\Delta E_{(\mathrm{S} 1)}\right)=-18.63-((-6.53)+(-12.78))=0.68$, which shows that $\mathrm{S} 31$ is not cooperative with respect to $\mathrm{S} 1$ and S22. Similarly, $\Delta E_{\mathrm{CE}(\mathrm{S} 42)}=\Delta E_{(\mathrm{S} 42)}-\left(\Delta E_{(\mathrm{S} 32)}+\Delta E_{(\mathrm{S} 1)}\right)=$ $-24.12-((-18.63)+(-6.54))=1.05$, or $\Delta E_{\mathrm{CE}(\mathrm{S} 43)}=\Delta E_{(\mathrm{S} 43)}-$ $2 \Delta E_{(\mathrm{S} 22)}=-24.69-2 \times(-12.78)=0.87$.

The atoms in molecule (AIM) theory applied to analyze the characteristics of the DHB bond critical points (BCPs) appeared in the aforementioned clusters. The parameters $\left(\nabla^{2} \rho_{\mathrm{BCP}}\right.$ is the Laplacian of electron density at BCP, and $H_{C}$ is the energy density at BCP and is the sum of the kinetic 
TABLE 6: Topological parameters for optimized clusters at MP2/6-311++G(d,p).

\begin{tabular}{|c|c|c|c|c|c|c|c|}
\hline Cluster & Bond & $\rho$ & $\nabla^{2}$ & $-G_{C}$ & $V_{\mathrm{C}}$ & $-G_{C} / V_{C}$ & $H_{C}$ \\
\hline S1 & $\mathrm{H} 4 \cdots \mathrm{H} 5$ & 0.0128 & 0.0368 & 0.0078 & 0.0065 & 1.2107 & -0.0014 \\
\hline \multirow{2}{*}{ S21 } & $\mathrm{H} 2 \cdots \mathrm{H} 9$ & 0.0121 & 0.0351 & 0.0074 & 0.0061 & 1.2212 & -0.0014 \\
\hline & $\mathrm{H} 3 \cdots \mathrm{H} 7$ & 0.0119 & 0.0355 & 0.0074 & 0.0060 & 1.2240 & -0.0014 \\
\hline \multirow{2}{*}{ S22 } & $\mathrm{H} 1 \cdots \mathrm{H} 12$ & 0.0128 & 0.0384 & 0.0081 & 0.0065 & 1.2359 & -0.0015 \\
\hline & $\mathrm{H} 2 \cdots \mathrm{H} 5$ & 0.0081 & 0.0256 & 0.0053 & 0.0042 & 1.2572 & -0.0011 \\
\hline \multirow{3}{*}{ S31 } & H1 $\cdots$ H16 & 0.0127 & 0.0378 & 0.0079 & 0.0064 & 1.2333 & -0.0015 \\
\hline & $\mathrm{H} 3 \cdots \mathrm{H} 7$ & 0.0082 & 0.0255 & 0.0053 & 0.0042 & 1.2585 & -0.0011 \\
\hline & $\mathrm{H} 4 \cdots \mathrm{H} 12$ & 0.0111 & 0.0327 & 0.0069 & 0.0059 & 1.2326 & -0.0013 \\
\hline \multirow{3}{*}{$\mathrm{S} 32$} & $\mathrm{H} 2 \cdots \mathrm{H} 11$ & 0.0073 & 0.0329 & 0.0045 & 0.0036 & 1.2609 & -0.0009 \\
\hline & $\mathrm{H} 4 \cdots \mathrm{H} 5$ & 0.0126 & 0.0355 & 0.0076 & 0.0063 & 1.2051 & -0.0013 \\
\hline & $\mathrm{H} 3 \cdots \mathrm{H} 16$ & 0.0147 & 0.0410 & 0.0089 & 0.0075 & 1.1837 & -0.0014 \\
\hline \multirow{4}{*}{ S41 } & $\mathrm{H} 1 \cdots \mathrm{H} 9$ & 0.0109 & 0.0324 & 0.0068 & 0.0055 & 1.2337 & -0.0013 \\
\hline & $\mathrm{H} 2 \cdots \mathrm{H} 16$ & 0.0111 & 0.0328 & 0.0069 & 0.0056 & 1.2317 & -0.0013 \\
\hline & $\mathrm{H} 3 \cdots \mathrm{H} 5$ & 0.0121 & 0.0366 & 0.0076 & 0.0061 & 1.2481 & -0.0015 \\
\hline & $\mathrm{H} 4 \cdots \mathrm{H} 17$ & 0.0083 & 0.0251 & 0.0052 & 0.0042 & 1.2514 & -0.0011 \\
\hline \multirow{4}{*}{ S42 } & $\mathrm{H} 1 \cdots \mathrm{H} 16$ & 0.0115 & 0.0335 & 0.0071 & 0.0058 & 1.2249 & -0.0013 \\
\hline & $\mathrm{H} 3 \cdots \mathrm{H} 5$ & 0.0120 & 0.0360 & 0.0075 & 0.0060 & 1.2494 & -0.0015 \\
\hline & $\mathrm{H} 4 \cdots \mathrm{H} 9$ & 0.0081 & 0.0257 & 0.0053 & 0.0042 & 1.2649 & -0.0011 \\
\hline & $\mathrm{H} 4 \cdots \mathrm{H} 17$ & 0.0106 & 0.0314 & 0.0066 & 0.0053 & 1.2341 & -0.0013 \\
\hline \multirow{4}{*}{ S43 } & $\mathrm{H} 2 \cdots \mathrm{H} 12$ & 0.0071 & 0.0222 & 0.0046 & 0.0037 & 1.2549 & -0.0009 \\
\hline & $\mathrm{H} 3 \cdots \mathrm{H} 18$ & 0.0077 & 0.0235 & 0.0049 & 0.0038 & 1.2634 & -0.0010 \\
\hline & $\mathrm{H} 4 \cdots \mathrm{H} 7$ & 0.0121 & 0.0368 & 0.0077 & 0.0062 & 1.2422 & -0.0015 \\
\hline & H4 $\cdots$ H14 & 0.0126 & 0.0377 & 0.0079 & 0.0064 & 1.2347 & -0.0015 \\
\hline
\end{tabular}

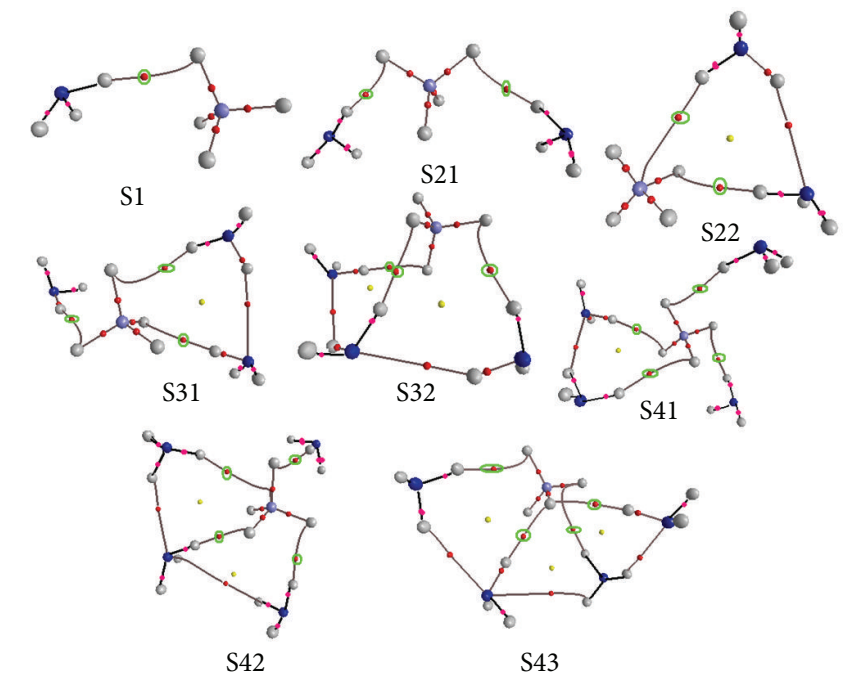

FIgURE 2: Molecular graphs of clusters between $\mathrm{BH}_{4}{ }^{-}$and $\mathrm{NH}_{3}$ at MP2/6-311++G(d,p) level.

electron energy density $\left(G_{C}\right)$ and the potential electron density $\left.\left(V_{C}\right)\right)$ are derived from the Bader theory and indicate the nature of interactions.

The molecular graphs and values of topological parameters for each intermolecular BCPs of clusters are given in Table 6 and Figure 2. All predicted DHBs of clusters under investigations have $\nabla^{2} \rho_{\mathrm{BCP}}>0,-G_{C} / V_{C}>1$, and
$H_{C}<0$; therefore they could be considered as interactions with noncovalent characters in their nature.

\section{Conclusion}

Results indicate the presence of negative cooperativity in $\mathrm{DHB}$ clusters of $\mathrm{BH}_{4}{ }^{-}$with $\mathrm{NH}_{3}$. It seems that the 
competition of $\mathrm{NH}_{3}$ molecules for taking electron density from a $\mathrm{BH}_{4}{ }^{-}$leads to such negative cooperativity. Also, CE inversely changes with the number of hydrogen bonds in the studied clusters. This part of negative cooperativity mainly arises from the weakening of $\mathrm{NH}_{3} \cdots \mathrm{NH}_{3}$ hydrogen bonds by DHB interactions.

\section{Acknowledgment}

The authors are very grateful to Mr. Amin Moazeni from the Chemistry Department in the University of Lethbridge for reading and correcting this paper.

\section{References}

[1] J. Ma, N. A. Choudhury, and Y. Sahai, "A comprehensive review of direct borohydride fuel cells," Renewable and Sustainable Energy Reviews, vol. 14, no. 1, pp. 183-199, 2010.

[2] E. Fakioğlu, Y. Yürüm, and T. N. Veziroğlu, "A review of hydrogen storage systems based on boron and its compounds," International Journal of Hydrogen Energy, vol. 29, no. 13, pp. 1371-1376, 2004.

[3] S. Srinivasan, D. Escobar, M. Jurczyk, Y. Goswami, and E. Stefanakos, "Nanocatalyst doping of $\mathrm{Zn}\left(\mathrm{BH}_{4}\right)_{2}$ for on-board hydrogen storage," Journal of Alloys and Compounds, vol. 462, no. 1-2, pp. 294-302, 2008.

[4] V. R. Fernandes, A. M. F. R. Pinto, and C. M. Rangel, "Hydrogen production from sodium borohydride in methanol-water mixtures," International Journal of Hydrogen Energy, vol. 35, no. 18, pp. 9862-9868, 2010.

[5] N. N. Greenwood and A. Earnshaw, Chemistry of the Elements, Butterworths-Heinemann, Oxford, UK, 2nd edition, 1997.

[6] M. Ziółkowski, S. J. Grabowski, and J. Leszczynski, "Cooperativity in hydrogen-bonded interactions: $a b$ initio and "atoms in molecules" analyses," The Journal of Physical Chemistry A, vol. 110, no. 20, pp. 6514-6521, 2006.

[7] I. Alkorta, J. Elguero, and M. Solimannejad, "Dihydrogen bond cooperativity in $(\mathrm{HCCBeH})_{n}$ clusters," Journal of Chemical Physics, vol. 129, no. 6, article 064115, 8 pages, 2008.

[8] H. Jacobsen, "Hydrogen and dihydrogen bonding of transition metal hydrides," Chemical Physics, vol. 345, no. 1, pp. 95-102, 2008.

[9] B. G. Oliveira and M. L. A. A. Vasconcellos, "The ethyl cation as proton donor for dihydrogen bonds in the $\mathrm{mC}_{2} \mathrm{H}_{5}^{+} \ldots \mathrm{nMgH}_{2}$ ( $m=1$ or 2 and $n=1$ or 2 ) complex: a theoretical study," Inorganic Chemistry Communications, vol. 12, no. 11, pp. 1142$1144,2009$.

[10] W. Zierkiewicz and P. Hobza, "The dihydrogen bond in $\mathrm{X}_{3} \mathrm{C}$ H. ..H-M complexes ( $\mathrm{X}=\mathrm{F}, \mathrm{Cl}, \mathrm{Br} ; \mathrm{M}=\mathrm{Li}, \mathrm{Na}, \mathrm{K})$. A correlated quantum chemical $a b$ initio and density functional theory study," Physical Chemistry Chemical Physics, vol. 6, no. 4, pp. 5288-5296, 2004.

[11] P. C. Singh and G. N. Patwari, "The C-H...H-B dihydrogen bonded borane-trimethylamine dimer: a computational study," Chemical Physics Letters, vol. 419, no. 1-3, pp. 265-268, 2006.

[12] R. C. Stevans, R. Bau, R. Milstein, O. Blum, and T. F. Koetzle, "Concept of the $\mathrm{H}(\delta+) \ldots \mathrm{H}(\delta-)$ interaction. A low-temperature neutron diffraction study of cis- $\left[\mathrm{IrH}(\mathrm{OH})\left(\mathrm{PMe}_{3}\right)_{4}\right] \mathrm{PF}_{6}$," Dalton Transactions Journal of the Chemical Society, no. 4, pp. 14291432, 1990.
[13] A. Zabardasti, A. Kakanejadifard, A.-A. Hoseini, and M. Solimannejad, "Competition between hydrogen and dihydrogen bonding: interaction of $\mathrm{B}_{2} \mathrm{H}_{6}$ with $\mathrm{CH}_{3} \mathrm{OH}$ and $\mathrm{CH}_{n} \mathrm{X}_{3-n} \mathrm{OH}$ derivatives," Dalton Transactions, vol. 39, no. 25, pp. 5918-5922, 2010.

[14] A. Zabardasti, M. Joshaghani, and M. Solimannejad, "Competition between hydrogen and dihydrogen bonding: interaction of $\mathrm{B}_{2} \mathrm{H}_{6}$ with $\mathrm{HF}$ and $\mathrm{LiH}$, Bulletin of the Chemical Society of Japan, vol. 83, no. 11, pp. 1359-1363, 2010.

[15] B. G. Oliveira, R. C. M. U. Araújo, and M. N. Ramos, "Multiple proton donors on $\mathrm{BeH}_{2} \ldots 2 \mathrm{HCl}$ trimolecular dihydrogenbonded complex: some theoretical insights," Journal of Structural Chemistry, vol. 19, no. 4, pp. 665-670, 2008.

[16] L. S. van der Sluys, J. Eckert, O. Eisenstein et al., "An attractive 'Cis-effect' of hydride on neighbor ligands: experimental and theoretical studies on the structure and intramolecular rearrangements of $\mathrm{Fe}(\mathrm{H}) 2(\eta 2-\mathrm{H} 2)(\mathrm{PEtPh} 2) 3$," Journal of the American Chemical Society, vol. 112, no. 12, pp. 4831-4841, 1990.

[17] W. T. Klooster, T. F. Koetzel, P. E. M. Siegbahn, T. B. Richardson, and R. H. Crabtree, "Study of the N-H...H-B dihydrogen bond including the crystal structure of $\mathrm{BH}_{3} \mathrm{NH}_{3}$ by neutron diffraction," Journal of the American Chemical Society, vol. 121, no. 27, pp. 6337-6343, 1999.

[18] R. H. Crabtree, "A new type of hydrogen bond," Science, vol. 282, no. 5396, pp. 2000-2001, 1998.

[19] A. Zabardasti, N. Zare, and M. Arabpour, "Theoretical study of dihydrogen bonded clusters of water with tetrahydroborate," Structural Chemistry, vol. 22, no. 3, pp. 691-695, 2011.

[20] S. Scheiner, Hydrogen Bonding: A Theoretical Perspective, Oxford University Press, Oxford, UK, 1997.

[21] J. G. Planas, C. Viñas, F. Teixidor et al., "Self-assembly of mercaptane-metallacarborane complexes by an unconventional cooperative effect: a C-H...S-H...H-B hydrogen/dihydrogen bond interaction," Journal of the American Chemical Society, vol. 127, no. 45, pp. 15976-15982, 2005.

[22] N. V. Belkova, T. N. Gribanova, E. I. Gutsul et al., "Specific and non-specific influence of the environment on dihydrogen bonding and proton transfer to $\left[\mathrm{RuH}_{2} \mathrm{P}\left(\mathrm{CH}_{2} \mathrm{CH}_{2} \mathrm{PPh}_{2}\right)_{3}\right]$," Journal of Molecular Structure, vol. 844-845, pp. 115-131, 2007.

[23] A. Zabardasti, A. Kakanejadi, S. Moosavi, Z. Bigleri, and M. Solimannejad, "Anticooperativity in dihydrogen bonded clusters of ammonia and $\mathrm{BeH}_{4}^{2-,}$, Journal of Molecular Structure, vol. 945, no. 1-3, pp. 97-100, 2010.

[24] V. I. Bakhmutov, Dihydrogen Bonds Principles, Experiments, and Applications, John Wiley \& Sons, 2008.

[25] P. Rodziewicz, K. S. Rutkowski, S. M. Melikova, and A. Koll, "Cooperative effects in blue-shifted hydrogen bonded cluster of $\mathrm{CF}_{3} \mathrm{H}$...(HF) $)_{1 \leq n \leq 3}$ from first principles simulations," Chemical Physics, vol. 361, no. 3, pp. 129-136, 2009.

[26] A. Zabardasti, A. Kakanejadi, F. Ghenaatian, and Z. Bigleri, "A theoretical study of cooperative and anticooperative effects on hydrogen-bonded clusters of water and the cyanuric acid," Molecular Simulation, vol. 36, no. 12, pp. 960-968, 2010.

[27] M. J. Frisch, G. W. Trucks, H. B. Schlegel et al., GAUSSIAN, Gaussian, Pittsburgh, Pa, USA, 2003.

[28] P. Hobza, V. Špirko, Z. Havlas et al., "Anti-hydrogen bond between chloroform and fluorobenzene," Chemical Physics Letters, vol. 299, no. 2, pp. 180-186, 1999.

[29] H. Matsuura, H. Yoshida, M. Hieda et al., "Experimental evidence for intramolecular blue-shifting C-H...O hydrogen bonding by matrix-isolation infrared spectroscopy," Journal of 
the American Chemical Society, vol. 125, no. 46, pp. 13910-13911, 2003.

[30] S. F. Boys and F. Bernardi, "The calculation of small molecular interactions by the differences of separate total energies. Some procedures with reduced errors," Molecular Physics, vol. 19, no. 4, pp. 553-566, 1970.

[31] R. F. W. Bader, F. Biegler-König, and J. Schönbohm, AIM2000A Program to Analyze and Visualize Atoms in Molecules, Version 2, University of Applied Sciences, Bielefield, Germany, 2002.

[32] P. Hobza and J. Šponer, "Structure, energetics, and dynamics of the nucleic acid base pairs: nonempirical ab Initio calculations," Chemical Reviews, vol. 99, no. 11, pp. 3247-3276, 1999.

[33] B. G. Oliveira, M. L. A. A. Vasconcellos, R. R. Olinda, and E. B. A. Filho, "Uncommon hydrogen bonds between a non-classical ethyl cation and $\pi$ hydrocarbons: a preliminary study," Journal of Structural Chemistry, vol. 20, no. 1, pp. 81-90, 2009.

[34] S. S. Xantheas, C. J. Burnham, and R. J. Harrison, "Development of transferable interaction models for water. II. Accurate energetics of the first few water clusters from first principles," Journal of Chemical Physics, vol. 116, no. 4, article 1493, 7 pages, 2002. 

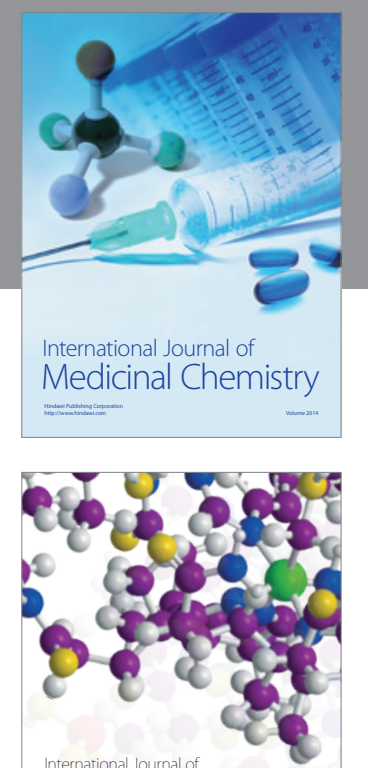

\section{Carbohydrate} Chemistry

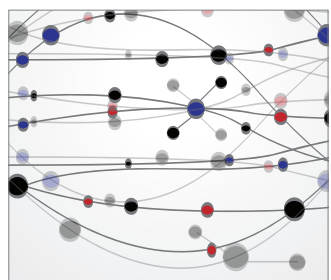

The Scientific World Journal
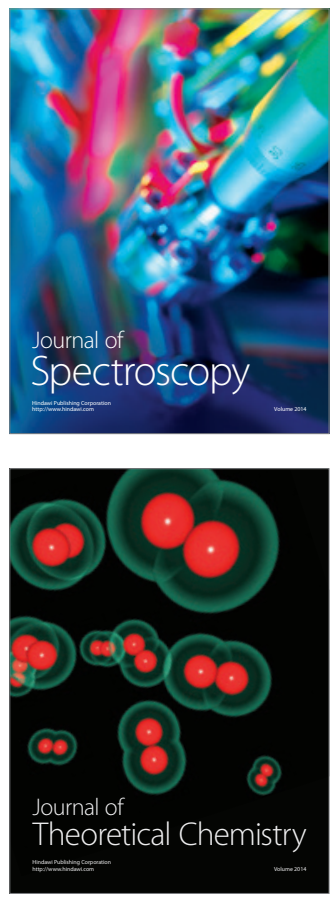
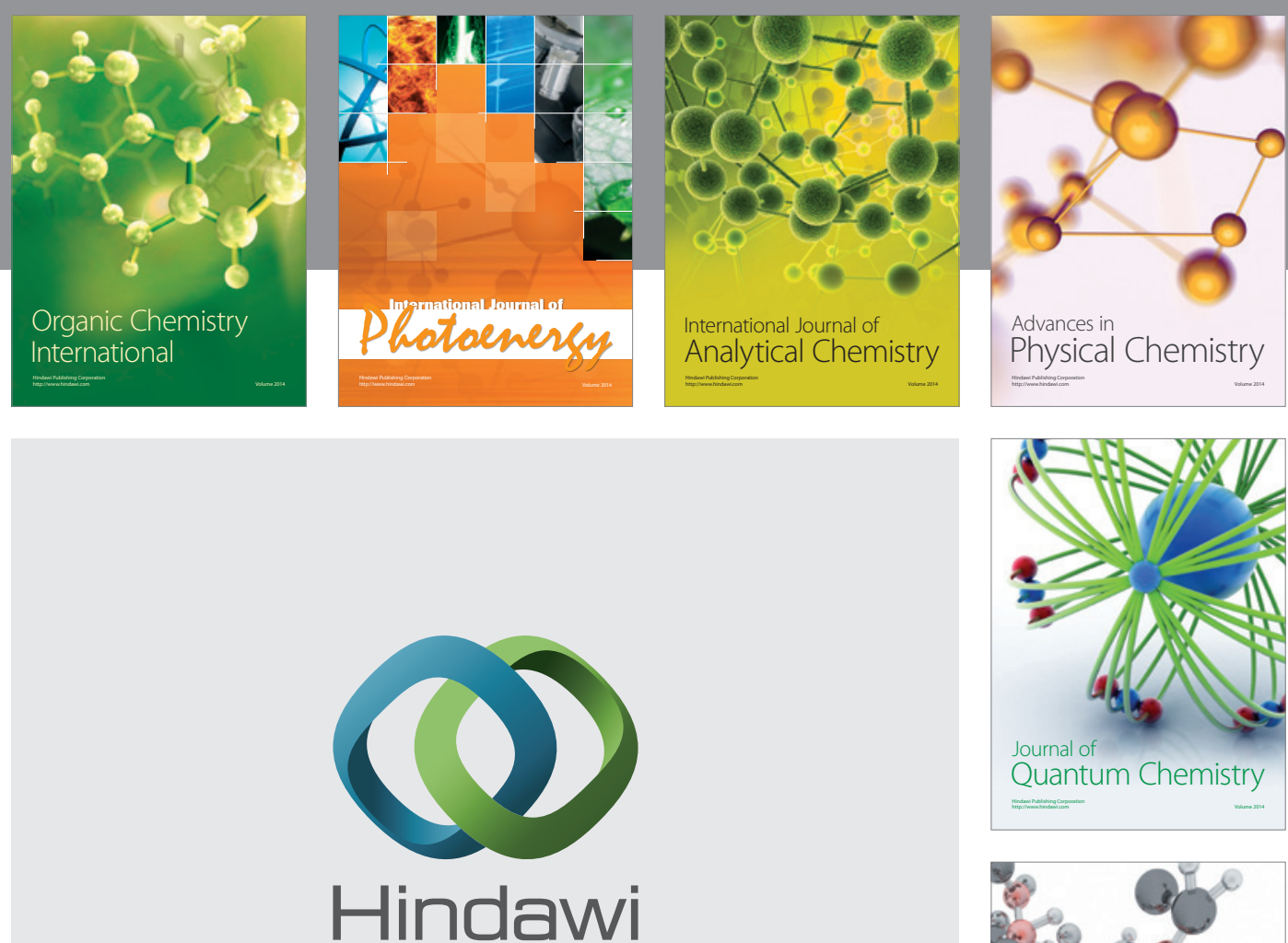

Submit your manuscripts at

http://www.hindawi.com

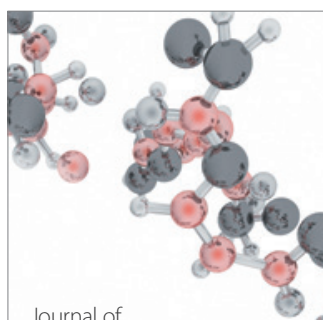

Analytical Methods

in Chemistry

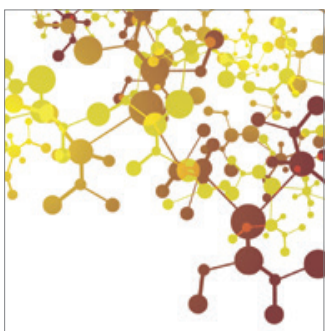

Journal of

Applied Chemistry

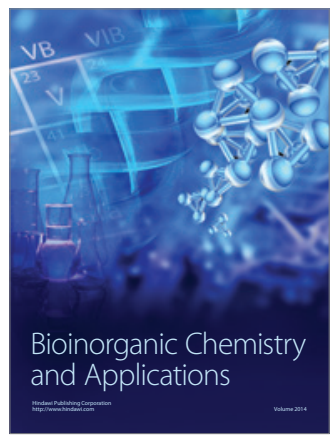

Inorganic Chemistry
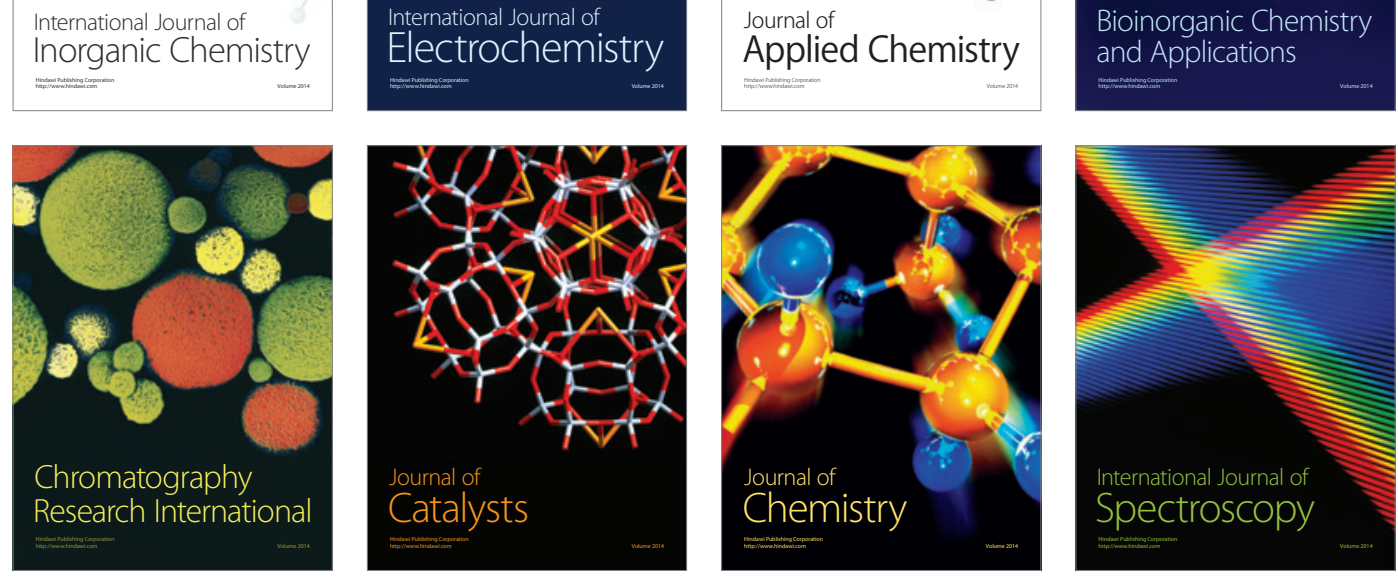